\title{
Research of the surge voltage protection by means of Hybrid Real-Time Power System Simulator
}

\author{
Sergey Stavitsky ${ }^{1, *}$, Yuri Borovikov ${ }^{1}$, and Yuly Bay ${ }^{1}$ \\ ${ }^{1}$ National Research Tomsk Polytechnic University, 634050 Tomsk, Russia
}

\begin{abstract}
The article considers the simulation of surge voltage protection. A functional diagram of this protection model and the means by which the researches were made are presented. The results are the oscillograms of the surge voltage protection operation for the generator.
\end{abstract}

\section{Introduction}

A voltage boost (for example, at the stator winding terminals) can lead to insulation failure and damage in the windings of the generator or transformer of the generator-transformer unit [1]. Dangerous voltage boost for the windings insulation result from the disappearance of the magnetic flux in the stator and a generator speed increase, which occurs when generation shedding is. Therefore, the turbo-generators with a capacity of $160 \mathrm{MW}$ or more are supplied with the surge voltage protection (SVP) [2]. Depending on the insulation state and the degree of overvoltage [3], the SVP can act either to turn off the generator (generator-transformer unit) or to a signal.

Today, there are various types of relay protection (RP) for generators [4] (electromechanical, microelectronic, and microprocessor). Demands are high for all types of protection. Due to the fact that of the above mentioned RP microprocessor devices are the newest and, therefore, the least tested [5]. Additionally, there is a growing tendency of their adoption into electric power systems (EPSs) [6]. As a result the microprocessor protection is of great significance for research in the Hybrid Real-Time Power System Simulator (HRTSim) among the developed RP modeling tools [7].

\section{Hybrid Real-Time Power System Simulator as a means of relay protection simulation}

Hybrid simulation is the simulation of the processes continuous spectrum in electric power equipment and EPS as a whole with all possible normal and emergency modes, without decomposition into quasi-steady-state processes, electromagnetic and electromechanical transient and supertransient processes [7]. The greatest advantage of HRTSim is the ability of hybrid modeling. HRTSim provides continuous valid three-phase mode modeling in real

* Corresponding author: $\underline{\text { sas4} @ @ \text { tpu.ru }}$ 
time and on an unlimited duration of processes in all possible operating modes of EPS. Moreover, HRTSim supports the information-control interactions between the created devices of flexible alternating current transmission system (FACTS [8, 9]), RP [10], emergency preventive automatics, etc.

Due to the above mentioned properties and abilities, HRTSim is able to solve reliably and efficiently the following problems of design, research and equipment operation:

- correct setting of various relay protection and emergency preventive automatics types with all possible modes of EPS;

- research and testing of established relay protection and emergency preventive automatics;

- current, retrospective and perspective analysis of real-time processes in equipment, including relay protection and emergency preventive automatics.

Fig. 1 shows the block diagram of information-control interactions of HRTSim with external means of relay protection and emergency preventive automatics

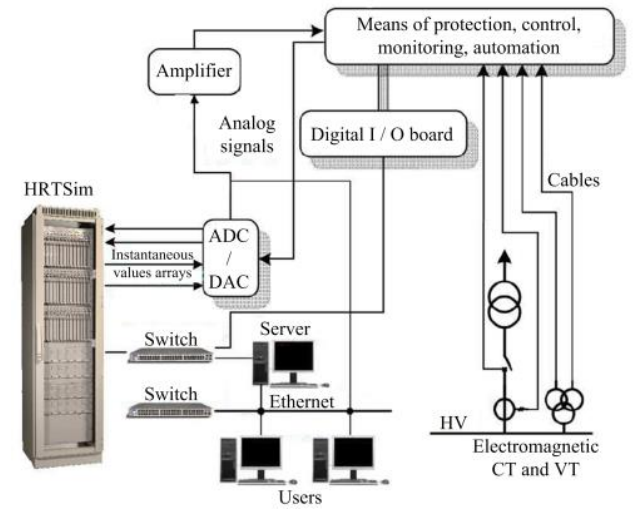

Fig. 1. Block diagram of information-control interactions of HRTSim with external means of relay protection and emergency preventive automatics.

\section{Surge voltage protection simulation}

In this section we present the results of the simulation of the surge voltage protection implemented in the microprocessor terminal, BMRZ-GR (Russia).

The developed SVP model operates according to the principle of comparison with the $\mathrm{U}_{\mathrm{svp}}$ (setting of the maximum effective voltage). The $\mathrm{U}_{\text {svp }}$ setting for the turbo-generators is $1.2 * \mathrm{U}_{\text {nom }}$, and for hydro-generators $(1.5-1.7) * \mathrm{U}_{\text {nom. }}$ The functional diagram (fig. 2) shows the algorithm for the SVP actions.

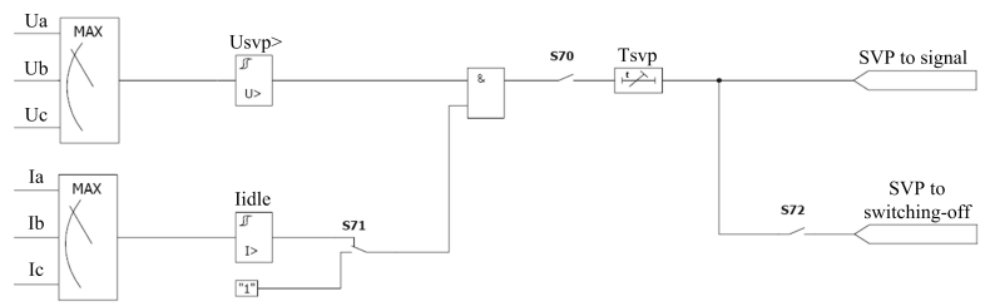

Fig. 2. Functional diagram of the algorithm for the SVP actions.

The SVP model has the ability to select an action to a switching-off or to a signal, similar to a real device. Additionally, the surge voltage protection has an idle current blocking. The blocking is set by default and the SVP only works if the generator is running 
on load and the maximum current is above the specified value $\mathrm{I}_{\text {idle }}$ (the generator is not idling).

Triggering of the SVP occurs via a time delay $\mathrm{T}_{\text {svp. }}$.

Fig. 3 shows the functional diagram of the SVP implemented mathematical model and its dynamic monitoring and control panel.

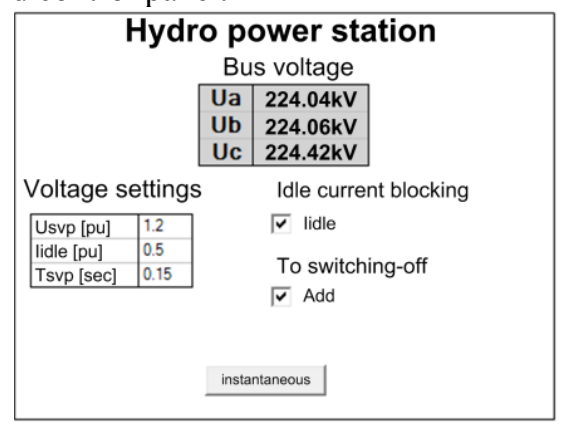

Fig. 3. Dynamic monitoring and control panel of SVP.

Voltage and current settings are set in relative nominal units.

Figure 4 shows oscillograms illustrating the process of increasing the voltage at the generator-transformer unit terminals caused by the load shedding on the $220 \mathrm{kV}$ hydro power station buses and the surge voltage protection model operation, which commands to turn off the generator.

Figure 5 shows oscillograms, according to which the SVP does not operate in a mode similar to the previous one, but with a smaller amount of load shedding.

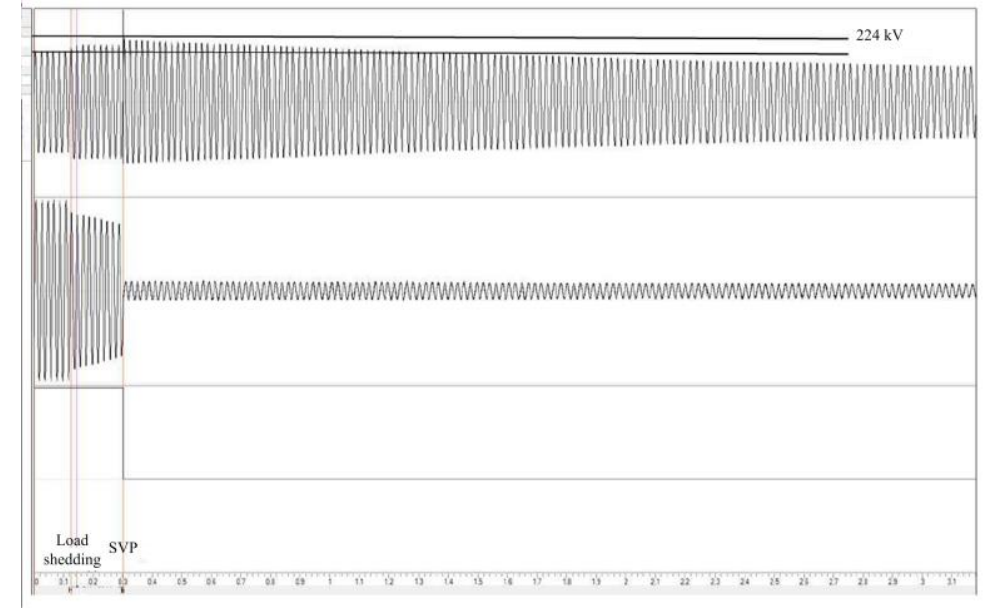

Fig. 4. Oscillograms of phase A voltage and current of the generator-transformer unit with a capacity of $210 \mathrm{MW}$ and a triggering signal of SVP at the load shedding on the $220 \mathrm{kV}$ buses. 


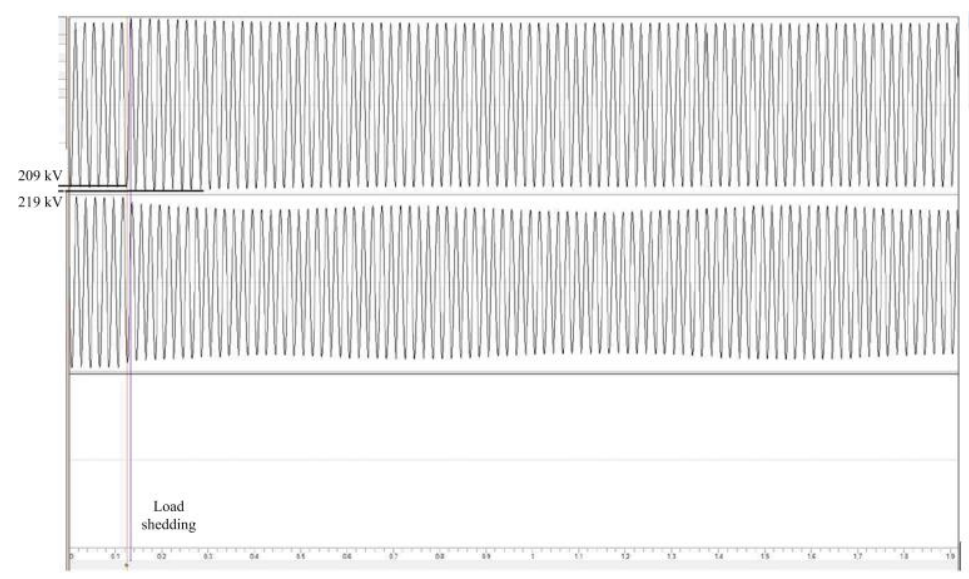

Fig. 5. Oscillograms of phase A voltage and current of the generator-transformer unit with a capacity of $210 \mathrm{MW}$ and the triggering signal absence of SVP at the load shedding on the $220 \mathrm{kV}$ buses.

\section{Conclusions}

The presented oscillograms confirm the valid operating of the SVP obtained model. The simulation results can be used to properly configure this type of relay protection for a particular object of the modeled EPS.

The reported study was funded by RFBR, according to the research project No. 16-38-60043 mol_a_dk.

\section{References}

1. M. Andreev, Y. Borovikov, N. Ruban, A. Khlebov, MATEC Web Conf. 91, 01048 (2016), DOI: 10.1051/matecconf/20179101048

2. S. Jeong, D. Shin, J. Kim, S. Kim, Asia-Pacific Int. Symp. Electromagnetic Compatibility, 7975464 (2017)

3. L. Chen, L. Yang, Y. Liu, Y. Huang, P.C. Wang, L. Xiao, J. Fusion Energy, 35 (2016)

4. P.M. Vahdati, H. Seyedi, A. Arjmandi, S. Moradi, Int. Trans. Electrical Energy Syst. 25 (2015), DOI: 10.1002/etep.1844

5. T. Bujanovic, P. Ghosh, 4th IEEE Int. Conf. Smart Energy Grid Eng, 7589552 (2016), DOI: 10.1109/SEGE.2016.7589552

6. O.V. Gnana Swathika, K. Karthikeyan, S. Hemamalini, R. Balakrishnan, ARPN J. Eng. Appl. Sci. 11 (2016)

7. M. Andreev, Y. Borovikov, N. Ruban, 11th Int. Forum Strategic Technol. 7884223 (2017), DOI: 10.1109/IFOST.2016.7884223

8. A. Gusev, A. Suvorov, A. Sulaymanov, IOP Conf. Series: Mater. Sci. Eng. 93, 012016 (2015), DOI: 10.1088/1757-899X/93/1/012016

9. R. Ufa, A. Vasilev, A. Gusev, A. Suvorov, 11th Int. Forum Strategic Technol. 7884204 (2017), DOI: 10.1109/IFOST.2016.7884204

10. N. Ruban, A. Sulaymanov, R. Ufa, I. Razzhivin, MATEC Web Conf. 91, 01050 (2016) 